\title{
Experimental Research and Analysis of Heating SMA Wire
}

\author{
Yachuan KUANG, Feng MIAO \& Xiaojie LIU \\ School of Civil Engineering, Central South University, Changsha 410075, China
}

Jieguang XIE

Foshan Electric Power Design Institute Co. Ltd., Foshan 528200, China

\begin{abstract}
In order to improve the heating rate of SMA in the field of active structural control and selfrepairing, the main factors influencing heating rate are studied and three improved methods are put forward: (1) Winding electrified enameled wire with high resistivity around SMA, and electrify the enameled wire; (2) Painting the surface layer of SMA with insulated glue, then electrify the SMA; (3) Winding enameled wire around SMA and painting the surface layer of enameled wire with insulated glue, and electrify the enameled wire. The heating rates of these three methods are compared with that of heating SMA directly through tests. The test results show that the method of using enameled wire to heat SMA indirectly can dramatically improve the heating rate, and when in SMA intelligent concrete, the way that painting insulated glue on the surfaces of SMA wires can effectively prevent the heat to be transferred to concrete, and improve the heating rate of SMA obviously.
\end{abstract}

KEYWORD: SMA; enameled wire; insulated glue; heating rate

As a new kind of smart alloy materials, SMA (Shape Memory Alloy) has a recoverable strain close to $8 \%$ and the yield stress can reach $700 \mathrm{MPa}$ at the austenitic temperature[1-2]. Besides, SMA have characteristics of greater driving force 、 high damping and it can be combined with concrete materials easily. Therefore, it has been widely studied and applied in the field of civil engineering[3-5]. Shape memory effect[6] is one of the main characteristic of SMA, scholars of the world have obtained a series of research results related to this characteristic[7-9], they put the prestretched SMA into a concrete beam as a drive, and then studied how it control the stress of structures and repair the cracks in structures automatically.

However, In these existing research findings, the most common way to drive SMA is to make it energized[10-12], and SMA has such low resistivity that it will take a long time and high current intensity to drive it (e.g. the current intensity to drive SMA up to $25 \mathrm{~A}$ in this literature[13]). Therefore, it has seriously affected driving efficiency of SMA and its control to structures. In addition, the heat generated by current will be transferred to concrete structures while heating SMA, which will make it hard for SMA to raise its own temperature and pose a threat to the safety of structures. This article will investigate the feasibility of indirect heating in SMA using electrified enameled wire and the performance of insulated glue through tests.

\section{EXPERIMENTAL PROGRAM}

According to previous experimental studies, there are basically two ways to heat SMA[14]: direct heating and indirect heating. Direct heating means that electrify SMA directly and use its electrical resistance to generate heat, the way has a simple design and can be controlled easily. Indirect heating means that using other heat sources to touch SMA. Because SMA have a high thermal conductivity $(10.6-19.8 \mathrm{~W} /(\mathrm{m}, \mathrm{K}))$, which can make heating itself more easily, so this paper proposed using electrified enameled wire with high resistivity to heat SMA, meanwhile, two kinds of insulated glue are painted to the surface layer of SMA in order to prevent the heat to be transferred to concrete.

\subsection{Test preparation}

\subsubsection{Test materials}

SMA in this test are from Xi'an Saite Metal Materials Development Company, it's material composition is Ti-50.8(at)\% Ni, length is $500 \mathrm{~mm}$, diameter is $3 \mathrm{~mm}$; Insulated glue are from Wanjun New Materials Company, one is black and another is transparent; electrified enameled wire's diameter is $0.35 \mathrm{~mm}$. 


\subsubsection{Surface treatment of SMA wires}

In order to compare the heating rate between direct heating and indirect heating, six different SMA specimens were designed: (1) The surface of SMA was done with nothing; (2) The surface of SMA was painted with black insulated glue; (3) The surface of SMA was painted with transparent insulated glue; (4) The surface of SMA was winded around electrified enameled wire; (5) The surface of SMA was winded around electrified enameled wire with black insulated glue; (6) The surface of SMA was winded around electrified enameled wire with transparent insulated glue, as shown in figure 1 and the surface characteristics of SMA wires are listed in table 1. Additionally, the thickness of insulated glue was $2 \mathrm{~mm}$ and the test would begin 4 days after the glue became hardened. Lastly, $25 \mathrm{~mm}$ long segment of specimen at the front end should be left, in order to measure the temperature of SMA easily.

Table 1.Surface characteristics of SMA specimens

\begin{tabular}{|c|c|c|c|c|}
\hline \multirow{2}{*}{$\begin{array}{c}\text { Heating } \\
\text { methods }\end{array}$} & \multirow{2}{*}{$\begin{array}{c}\text { Specimen } \\
\text { number }\end{array}$} & \multicolumn{2}{|c|}{ Insulated glue } & $\begin{array}{c}\text { Electrified } \\
\text { enameled wire }\end{array}$ \\
\cline { 2 - 5 } & Transparent & Black & $0.35 \mathrm{~mm}$ \\
\hline \multirow{2}{*}{$\begin{array}{c}\text { Direct } \\
\text { heating }\end{array}$} & 1 & - & - & - \\
\cline { 2 - 5 } & 2 & - & $\sqrt{ }$ & - \\
\hline \multirow{2}{*}{$\begin{array}{c}\text { Indirect } \\
\text { heating }\end{array}$} & 4 & $\sqrt{ }$ & - & - \\
\cline { 2 - 5 } & 5 & - & $\sqrt{ }$ & $\sqrt{ }$ \\
\cline { 2 - 5 } & 6 & $\sqrt{ }$ & - & $\sqrt{ }$ \\
\hline
\end{tabular}

*Notes: “-”,stands for NO, “ $\sqrt{ }$ ”stands for YES

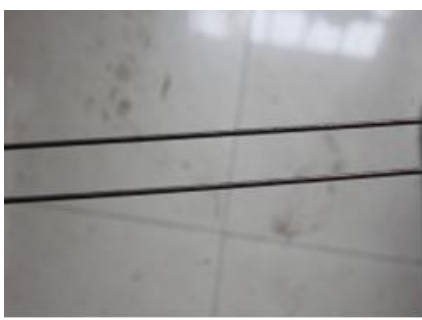

(a) specimen 1

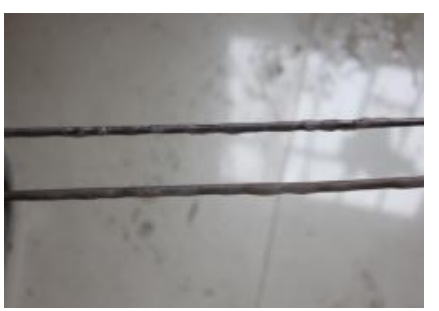

(c) specimen 3

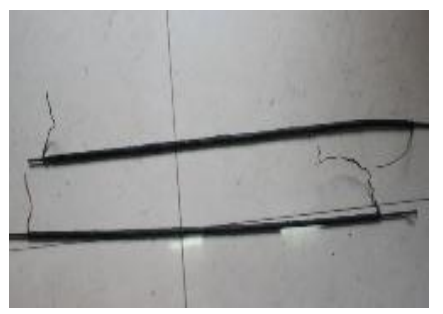

(e) specimen 5

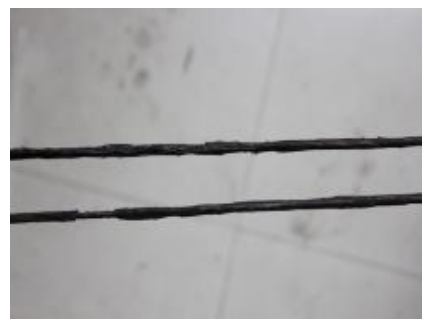

(b) specimen 2

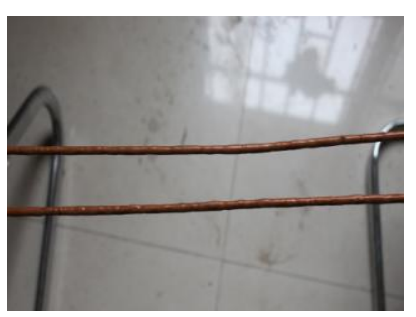

(d) specimen 4

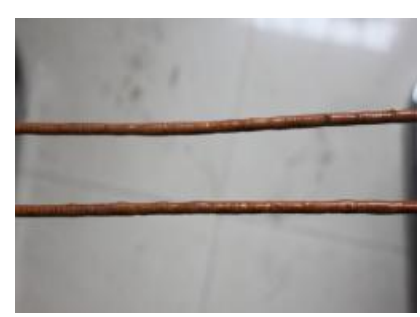

(f) specimen 6

\subsubsection{Temperature collection}

During the test, the temperatures were measured by thermocouple thermometer and collected by computer automatically. For the specimens in the group of directing heating, we only need to measure SMA wires' own temperatures, so one thermocouple thermometer is enough. While, for the indirect heating group, two thermocouple thermometers were needed, one was attached to the surface layer of SMA, and another was attached to the surface layer of electrified enameled wire or insulated glue.

\subsection{Test process}

For the specimen 1, 2, 3, the SMA wires were electrified directly and the current intensity were 9A and 11A. For the specimen 4、5、6, the SMA wires were heated by energized electrified enameled wire indirectly, and the current intensity were 4A and 5A because of its high resistivity. The following image shows the test devices.

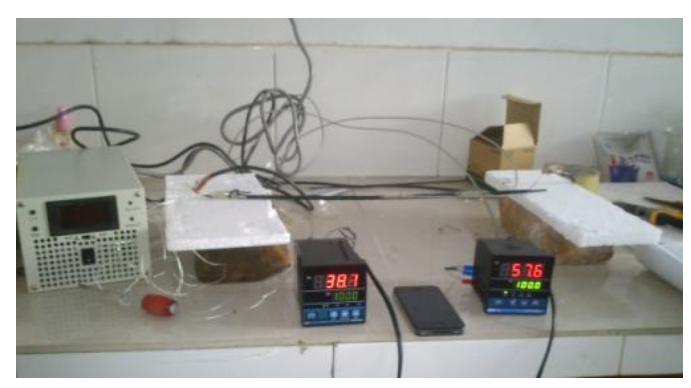

Figure 2.Electric incentive test of SMA

\section{TEST RESULTS AND ANALYSIS}

\subsection{Heating curves}

Figure 3 shows the temperature-time curves of different current intensities.

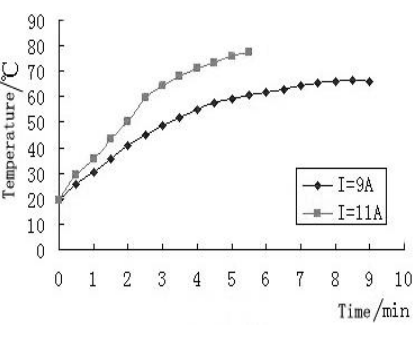

(a) specimen 1

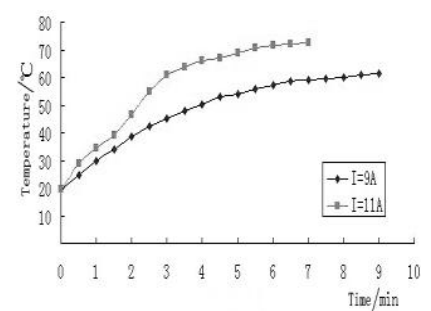

(c) specimen 3

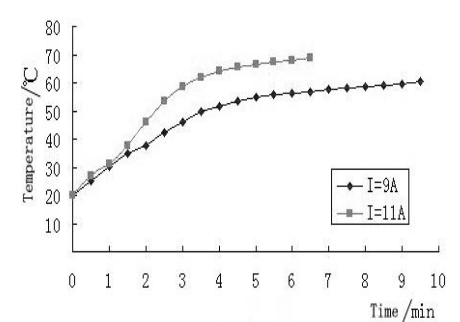

(b) specimen 2

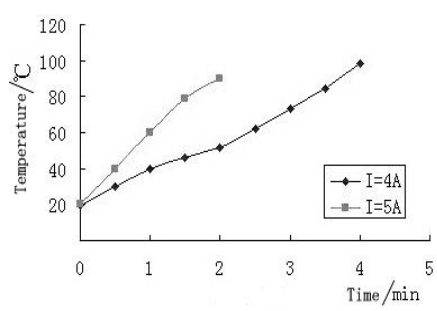

(d) specimen 4

Figure 1. Surface treatments in each specimen 


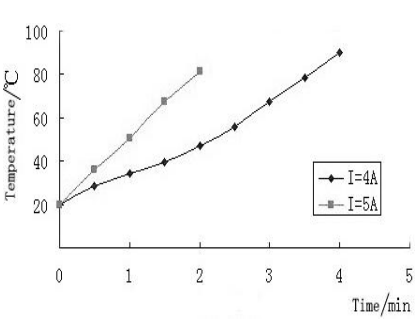

(e) specimen 5

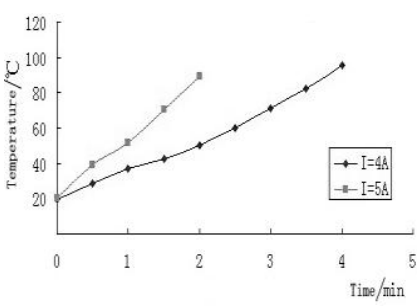

(f) specimen 6
Figure 3.Heating curves of SMA

As can be seen from the heating curves above, in the group of direct heating test, the temperatures of SMA wires tend to be gentle after increasing to a certain extent (e.g. the temperature of specimen 1 become gentle after increasing to $66^{\circ} \mathrm{C}$ ), This is because that the heat of this system has reached equilibrium. And the higher the current intensity, the higher extent the temperature will increase to. Meanwhile, in the group of indirect heating test, the heating curves are steep, and the heating rate of SMA wires is high.

In addition, when the current intensity is the same, the heating rate of specimen 2 and 3 is lower than that of specimen 1 , and the heating rate of specimen 5 and 6 is also lower than that of specimen 4. Because the surfaces of specimen 2、3、4 and 5 are painted with insulated glue at the thickness of 2 $\mathrm{mm}$, and the thermal conductivity of air $(0.023 \mathrm{~W} / \mathrm{m} \cdot \mathrm{K})$ is much lower than that of insulated glue $(0.482 \sim 0.567 \mathrm{~W} / \mathrm{m} \cdot \mathrm{K})$ under laboratory conditions, so for the specimens with insulated glue, quite a lot of heat will be transferred to insulated glue, and then the heating rate of specimens is little lower than that of specimens without insulated glue. However, the thermal conductivity of concrete is $1.335 \sim 1.695 \mathrm{~W} / \mathrm{m} \cdot \mathrm{K}$, which is much higher than that of insulated glue, therefore, when in SMA intelligent concrete, the way that painting insulated glue on the surfaces of SMA wires can improve the heating rate of SMA obviously.

\subsection{Heating rate analysis}

The reverse martensitic transformation temperature of SMA in the test is $60.5^{\circ} \mathrm{C}$, the time needed to reach $60.5^{\circ} \mathrm{C}$ and the average heating rate for each specimen at different current intensities are shown in table 2.

As table 2 shows, for each specimen, the higher the current intensity, the higher the heating rate. For the specimen 1 (the surface of SMA was done noting), To reach the target temperature $\left(60.5^{\circ} \mathrm{C}\right)$, it needs $157 \mathrm{~s}$ and its average heating rate is $0.385^{\circ} \mathrm{C} / \mathrm{s}$ at the current intensity of $11 \mathrm{~A}$. While, the specimen 4 (the surface of SMA was winded around electrified enameled wire) only needs $147 \mathrm{~s}$ and its average heating rate is $0.412^{\circ} \mathrm{C} / \mathrm{s}$ at the current intensity of 4A. When the current intensity increases to $5 \mathrm{~A}$, the time is $69 \mathrm{~s}$ and its average heating rate is $0.877^{\circ} \mathrm{C} / \mathrm{s}$.
Therefore, the average heating rate of specimen 4 is 1.07 and 2.28 (at 4A and 5A) times higher than that of specimen 1 (at 11A).

Table 2.Heating rate of SMA

\begin{tabular}{|c|c|c|c|c|}
\hline \multirow{2}{*}{$\begin{array}{l}\text { Heating } \\
\text { methods }\end{array}$} & \multirow{2}{*}{$\begin{array}{l}\text { Specimen } \\
\text { number }\end{array}$} & $\begin{array}{l}\text { Current } \\
\text { intensity }\end{array}$ & Time & $\begin{array}{c}\text { Heating } \\
\text { rate }\end{array}$ \\
\hline & & $\mathrm{A}$ & $\mathrm{s}$ & ${ }^{\circ} \mathrm{C} / \mathrm{s}$ \\
\hline \multirow{6}{*}{$\begin{array}{c}\text { Direct } \\
\text { heating }\end{array}$} & \multirow{2}{*}{1} & 9 & 327 & 0.185 \\
\hline & & 11 & 157 & 0.385 \\
\hline & \multirow{2}{*}{2} & 9 & 609 & 0.099 \\
\hline & & 11 & 197 & 0.307 \\
\hline & \multirow{2}{*}{3} & 9 & 494 & 0.123 \\
\hline & & 11 & 178 & 0.340 \\
\hline \multirow{6}{*}{$\begin{array}{l}\text { Indirect } \\
\text { heating }\end{array}$} & \multirow{2}{*}{4} & 4 & 147 & 0.412 \\
\hline & & 5 & 69 & 0.877 \\
\hline & \multirow{2}{*}{5} & 4 & 163 & 0.371 \\
\hline & & 5 & 86 & 0.703 \\
\hline & \multirow[b]{2}{*}{6} & 4 & 152 & 0.398 \\
\hline & & 5 & 78 & 0.776 \\
\hline
\end{tabular}

Similarly, the average heating rate of specimen 5 is 1.21 and 2.29 (at $4 \mathrm{~A}$ and $5 \mathrm{~A}$ ) times higher than that of specimen 2 (at $11 \mathrm{~A}$ ). And the average heating rate of specimen 6 is 1.17 and 2.30 (at $4 \mathrm{~A}$ and $5 \mathrm{~A}$ ) times higher than that of specimen 3 (at 11A). Therefore, using electrified enameled wire to heat SMA indirectly can greatly improve the heating rate, for the heating rate is 1.1 2.3 times higher than that of heating SMA directly, even though the current intensity is $1 / 3 \sim 1 / 2$ of that of heating SMA directly.

At last, the surfaces of specimen 2 and 5 are painted with black insulated glue, and the surfaces of specimen 3 and 6 are painted with transparent insulated glue. Meanwhile, the heating rate of specimen 3 is 1.24 and 1.11 (at $9 \mathrm{~A}$ and $11 \mathrm{~A}$ ) times higher than that of specimen 2 , and the heating rate of specimen 6 is 1.07 and 1.10 (at 4A and 5A) times higher than that of specimen 5. Therefore, the performance of transparent insulated glue is better than that of black insulated glue.

\section{CONCLUSION}

(1) SMA wire's resistivity is so low that when using its own resistance to generate heat, it takes a long time and a high current intensity to drive SMA wire, and that will greatly affect the efficiency of driving SMA and its control to structures.

(2) Electrified enameled wire has a high resistivity, and the way that using electrified enameled wire to heat SMA indirectly can greatly improve the heating rate of SMA, for the heating rate of indirect heating way is $1.1 \sim 2.3$ times higher than that of direct heating way even though the current intensity is $1 / 3 \sim 1 / 2$ of that of heating SMA directly. 
(3) For SMA intelligent concrete, the way that painting insulated glue on the surfaces of SMA wires can effectively prevent the heat to be transferred to concrete and improve the heating rate of SMA obviously. In addition, the performance of transparent insulated glue is better than that of black insulated glue.

\section{ACKNOWLEDGEMENTS}

The authors thank the financial support from National Natural Science Foundation of China (51008314, 51108459) and Innovation Team of Ministry of Education (IRT1296).

\section{REFERENCES}

[1] ZHAO Liancheng, CAI Wei, ZHEN Yufeng 2002. Shape Memory Effect and Super Elasticity of Alloys. Beijing: National Defence Industry Press.

[2] KUANG Yachuan, OU Jinping 2008. Research on the Deformation Characteristics of Smart Concrete Beam Embedded with Shape Memory Alloy Wires. China Railway Science, 29(4): 41-46.

[3] CUI Di, LI Hongnan, SONG Gangbing 2005. Progress on Study and Application of Shape Memory Alloy in Civil Engineering. Journal of Disaster Pnevention and Mitigation Engineering, 25(1): 86-87.

[4] Prokoshkin S D,Korotitskiy A V,Brailovski V,et al 2004.On the Lattice Parameters of Phases in Binary TiNi Shape Memory Alloys. Acta Materialia, 52(15): 4479-4492.
[5] McCormick J, DesRoches R, Fugazza D, et al 2006. Seismic Vibration Control U sing Superelastic Shape Memory Alloys. Journal of Engineering Materials and Technology, 128:294-301.

[6] HUANG Yibin, WANG Gaochao 2003. Progress in Research on Shape Memorry Alloy. Journal of International Metal Working, 24(1):56-58.

[7] Song G, Mo Y L, Otero K and Gu H 2006. Health Monitoring and Rehabilitation of A Concrete Structure Using Intelligent Materials. Smart Mater Struct, (15):309314.

[8] SHIMAMOTO A, FURUYAMA Y, ABE H 2007. Effect of Fatigue Crack Propagation in the Shape Memory Alloy Fiber Reinforced Smart Composite. Key Engineering Materials. (3):1093-1096.

[9] YAN Shi, SUN Jing, WANG Wei 2010. Deformation Property of Smart Concrete Continuous Beams Reinforced with Shape Memory Alloy Rebars. Concrete, (3): 8-12.

[10] CUI Di, GUAN Ping 2011. Rehabilitation of Concrete Beam by Using Martensitic Shape Memory Alloy Strands. Advanced Materials Research, (5): 243-249.

[11] DI Shengkui, HUA Weipan 2010. Self-monitoring and Self-repairing of Crack in Concrete Beam with Constraint Super-elastic SMA. Journal of Building Materials, 13(2):237-242.

[12] Brdaux J.E., Manson. J.A., Gotthardt R.1997. Active Stiffening of Composite Materials by Embeded Shape Memory Alloy Fibers. Materials Research Society Symposium, 107-117.

[13] ZHOU Lili 2005. Experimental and Theoretical Study on the Shape Memory Alloy Smart Prestressed Beams. Shanghai: Tongji University, School of Engineering.

[14] YANG Jie, WU Yuehua 1993. Shape Memory Alloy and its Applications. Hefei: University of Science and Technology of China Press. 